\title{
A research on Exterior Wall Coating Based on Environmental Protection and Automatic Spraying Technology
}

\author{
Yixuan $\mathrm{HOU}^{1, \mathrm{a}}$ and Jingrong $\mathrm{WU}^{2, \mathrm{~b}}$ \\ ${ }^{1}$ Jilin University, China \\ ${ }^{2}$ Hubei University of Technology Engineering and Technology College,China \\ a136388223@qq.com, b864877562@qq.com
}

\begin{abstract}
As the main material for building facing decoration, building exterior wall coating can protect and decorate the building in the process of construction ${ }^{[1]}$. Exterior wall coating is characterized by low cost, convenient installation, rich colors and so on, so it has a wide application in building exterior walls. At present, due to the requirements for energy saving and environmental protection as well as the complexity of installation, application of exterior wall tiles is in decline ${ }^{[2]}$. Besides, with the automatic machine technology becoming more mature, there is an increasing application of exterior wall coating. This paper is designed to conduct an analysis on the wide application prospect of current exterior wall coating based on the advantages of it and the maturity of automatic spraying technology.

Keywords: building exterior wall; coating; advantages; automatic spraying robot; application
\end{abstract}

\section{Introduction}

Since reform and opening up, the city construction in China has been changed rapidly and new buildings have sprung up. Architects express their own ideas as to architectural concepts and times by the help of applying materials. With people's growing demands for decorating buildings and awareness towards energy saving, facing decoration has become more important for a building.Nowadays, there are three primary materials which are coating, wall tile and reflective glass curtain.

\section{The Evolution of Exterior Wall Facing Tiles}

Facing tiles ${ }^{[3]}$ has improved the traditional cement motar pasting method by introducing the dry hanging techniques of veneer which has gradually replaced the traditional method of hanging metal wire before filling in cement motar. As for concrete-structured buildings, the decorative concrete directly applied on its facing has also become a new technique as to building exterior wall decoration in China. Besides, there are also reflective glass curtains whose operating method can not only reduce the dead weight of the building but also improve its functions and decoration effect. Reflective glass curtains have exerted great influence on the development of high-rise building exterior wall decoration. In the early 
days of $20^{\text {th }}$ century, most building exterior walls in China are bare concrete walls but after the reform and opening up, with the development of national economy, people start to set higher requirements for building exterior wall decoration. Since then, all sorts of new technology, materials, techniques and equipment have been more and more used in the construction of exterior wall facing decoration. The exterior wall facing has been evolved from bare concrete wall, sand-lime bricks, to paste colored gravel stones with cement and even paste mosaic, polishing slates, colored glazed tiles, marble, etc. Facing tiles have improve the traditional

\section{The Advantages and Disadvantages of Exterior Wall Tiles}

Advantages: exterior wall tiles are numerous in variety and are firm and durable so that they have satisfying durability and texture. The bright colors present rich decorative effects. In the meanwhile, they play an important role in protecting the wall, winter protection and heat preservation because they are acid and alkali proof as well as stable as to physical and chemical properties.

The Disadvantages are Becoming more Prominent

Safety Concerns

In the recent years, news is often heard Passers-by are hurt by the explosion and falling of the exterior wall tiles of residence, hospitals, schools and so on. Exterior wall tiles are apt to fall down or be damaged which have become a obstinate problem. This problem is related to the features of ceramic tiles and installation techniques because seam as a result of blocks of tiles pasted together allows for easy water penetration while in extremely cold areas, the inspersed water will form ice with a large size and thus cracked walls cause bad consequences. Moreover, the base of ceramic tiles will be corroded and decomposed so they will lost the ability to adhere to the wall and are prone to falling down.

Environmental Protection Concerns

Producing exterior wall tiles is a process consuming high energy and massive resources ${ }^{[3,4]}$. The production will consume a great number of porcelain clay, feldspar, quartz and many other mineral resources and requires a temperature of as high as $1,000^{\circ} \mathrm{C}$ to burn them which only consumes considerable coal, natural gas and electricity resources but also produce loads of waste gas, dust and waste water. What's more, the comparatively heavy dead weight of the facing tiles will increase the burden to the buildings. To sum up, tiles production is a cumbersome, highly polluting and energy intensive industry so in view of the environmental protection ideology proposed by the international community, this industry is bound to be restricted.

\section{Overview of the Exterior Wall Coating}

The exterior wall coating is being valued by people for its rich color, high safety, low cost, less burden to the building, easy operation, short construction time, easily renewable, low energy consumption in production, environmentally-friendly, low dead weight, degradable and many other features ${ }^{[5]}$.

The Current Situation of Coating both at Home and Abroad

For the moment, building exterior wall coating has become the mainstream in exterior wall decoration in foreign countries. As much as $80 \%$ foreign buildings adopt exterior wall coating to decorate the facing and acrylic and styrene acrylicand so forth are the principle types that are widely used in exterior wall coating among which silicon ${ }^{[4]} \mathrm{e}$-acrylic coating, polyurethane coating and fluorocarbon with better performance have become the main varieties in exterior wall facing of high-rise buildings in foreign countries. However, the 
application of exterior wall coating started late in China and due to poor quality control, in two or three years, there appear loss of light, color fading, peeling off of the coating, striping and chalking of the coating and other aging phenomenon which severely affect the decorative effect of the exterior wall decoration. What's worse, the consumption idea that coating is a cheap decoration and it is not suitable for high end exterior wall decoration which hampers the popularization and application of building exterior wall coating. After years of research and development, exterior wall coating has become more mature and the variety more diversified. There are modified exterior wall coating with high performance mainly represented by acrylic acid, organic/ inorganic composite coating, water-borne silicone-modified acrylic polyurethane coating, water-borne acrylic polyurethane coating and modified fluorocarbon resin coating, etc. With the introduction of advanced foreign technology and raw material, people have a better knowledge towards exterior wall coating and thus the application of exterior wall coating in China has been greatly improved.

Variety of Exterior Wall Coating

The main varieties of exterior wall coating are as follows:

1emulsion type of acrylic acid exterior wall coating is a water paint with faint smell, fast drying after operation and safe and nontoxic ability.

2 Granite ploychrome exterior wall coating is a liquid ploychrome coating made from acrylic acid modified emulsion.

3 water-borne silicone-modified acrylic polyurethane coating is a type of emulsion made from methylsilicone oil whose unsaturated bonds contain specific molecular weight and Regular acrylic monomers after emulsion copolymerization in a special condition.

4 water-borne polyureathane resin is glossy and has good waterproof, weatherability and mechanical properties.

5 fluorine resin with high weatherability shows great weatherability, waterproof, dirt resistance, and acid and alkali proof but the cost is high so it is less developed in China.

6 organic/ inorganic composite coating

The Appearance of Exterior Wall Coating

There are mainly four expression forms of coating appearances:

1 smooth coating: lusterless coating and translucent coating 。

2 stereoscopic coating: sand like coating, textured coating, napping coating, coating with rised pattern, mountain like coating.

3 Coating with multiple layers of stippling: ploychrome planar coating, ploychrome uneven coating

4 Printing decoration: pattern printing reflex coating, textured printing reflex coating

By means of the above expression forms, it is viable to make water-borne granite coating, wall paint instead of rock material, embossing paint,diatom mud paint, acrylic acid uneven paint and so on. The wide variety of the paint greatly enriches the facing of the building.

\section{The Application of Automatic Spraying Robots}

With the improvement of exterior wall coating and maturity of supporting machines, automatic spraying technology ${ }^{[6]}$ will become a highlight. Now, automatic spraying robots have been used to the installation of building exterior wall coating.

In foreign countries, automatic spraying technology is already mature with a research and development history dating back to over thirty years ago. Currently, many domestic researches concentrate on modeling analysis and trajectory optimization of spray guns which have been utilized in astronautical technology, aircraft and automobile production in a mature way. As the combination of robotic technology and spraying technology, spraying 
robot is a kind of special robot mainly used to coat the surface. The spraying robot can meet the demands of environmental protection, efficiency and flexible production and for these reasons, it is highly anticipated that spraying robot will replace human forces in modernized spraying operating line. Construction industry is considered to be an energy intensive, highly risky and labor intensive industry and spraying robots as special industrial robot can lower the intensity of labor. It also has other features: firstly it has a flexible trajectory and exact location control to create a coating with equal thickness; secondly, the flexibility of the robot contributes to wider scope for it can deal well with corners or seam of the building; thirdly, its work will not be affected by weather so that work efficiency is improved and the outside work will be less dangerous. At present, the operation of building exterior walls are in great need of labor so it is necessary for engineers and technicians to increase their research and input into automatic control and therefore release construction workers from the peril of work.

\section{Conclusion}

In recent years, environmental protection and energy saving of buildings have become state policies of China. Building exterior wall coating has a wider application because of its rich texture, rich colors, resistance to cracking, good weatherability and other advantages. With the more mature exterior wall coating techniques, the deepening application of robotic spraying technology, the development of advanced control theory and new sensor technology, the exterior wall coating will definitely bring us cities full of vigor and colors.

\section{References}

1. Xing Qizhang, Discussion on the Application of Building Exterior Wall Coating on Building Facing -Technology and Enterprise, 2012, (11)-2012

2. Cao Ganting, Decorate the City with Environmental Environmentally-friendly New Materials -Residence in Cities 2012(4)

3. Li Zhihua \& Zheng Ziqiao Advances in Research and Development of High-performance Exterior Wall Coating -Coating Industry 1999

4. Lu Zhengquan, Yang Jianjun, Zhang Jian'an, Wu Qingyun \& Wu Mingyuan, The Application and Research Advances of Water-borne Acrylates Coating in Construction Area -Coating Technology and Digest, 2014

5. Wang Yongkang, The Application of Building Coating in Building Facing Decoration -Theoretical Research on City Construction, 2014

6. Wang Fengchao[1], Wang Liping[2], Liang Xincheng[2], Zhao Jingshan[2], Qiu Yunjie [3], Current Research and Advances in Intelligent Spraying Robots -Science and Technology across China, 2014 